\title{
Autonomía y libertad de cátedra universitaria en América Latina en tiempos de globalización
}

\section{Autonomy and Freedom of University Chair in Latin America in Globalization Times}

\author{
María Gabriela Hernández López \\ Universidad Nacional \\ Costa Rica \\ maria.hernandez.lopez@una.cr
}

Recibido: 23/05/2019 Aceptado: 04/09/2019

Resumen. Esta ponencia hace una caracterización de la evolución del Estado, desde el enfoque de autores como William Robinson, a partir de la teoría de la globalización. De forma complementaria, en este análisis se hace referencia a las fases de formación del Estado en América Latina planteadas por Pastrana y Castro desde la colonia al día de hoy, misma que relacionaremos con otras variables, como la evolución de la institución de la educación superior universitaria de carácter estatal y sus constructos sociales, la autonomía universitaria y la libertad de cátedra, en una etapa actual del desarrollo del Estado, en medio del fenómeno llamado globalización.

Palabras clave: globalización, autonomía, libertad de cátedra, Estado, universidades públicas.

\begin{abstract}
This paper describes the evolution of the State from the approach of authors like William Robinson, and based on the theory of globalization. Besides, in this analysis reference is made to the phases of the State formation in Latin America proposed by Pastrana and Castro from colonial times to present. We will relate this reference to other variables, such as the evolution of of the State institution of higher university education and its social constructs, university autonomy, and academic freedom, in the current stage of the development of the State, in the midst of the phenomenon called globalization.
\end{abstract}

Keywords: globalization, autonomy, academic freedom, State, public universities. 


\section{Introducción}

El objetivo de este estudio es contribuir a la reflexión sobre componentes de consideración del actual contexto histórico y proceder de las universidades públicas latinoamericanas en procesos de cambio, en un mundo cada vez más globalizado.

Autores como William Robinson aportan elementos sobre el sistema mundo actual, en el marco de lo que él denomina globalización, del cual crea una teoría para su análisis, desde la que se hará el abordaje de algunos temas específicos en materia de institucionalidad universitaria pública.

Robinson es un autor muy cercano a Imanuel Wallerstein (1999) en el estudio del sistema capitalista, su aporte se reconoce por el análisis del enfoque sistémico de este modelo mediante su teoría de la globalización. Carlos Tünnermann complementa sobre este enfoque de globalización neoliberal al señalar que,

Wallerstein nos habla de una economía o sistema mundo, en el sentido de que todos los estados nacionales están en diferentes grados, integrando una estructura económica central. El concepto de «globalización» no se limita al aspecto puramente económico; en realidad, es un proceso multidimensional que comprende aspectos vinculados a la economía, las finanzas, la ciencia y la tecnología, las comunicaciones, la educación, la cultura, la política, etc... (2005, p. 15)

Robinson (2015) en su capítulo primero, además de aportar elementos importantes para la reflexión-acción, amplía y redefine, según la coyuntura actual, algunos conceptos, como el de Estado, que se han estado manejando como únicos y estáticos. Es claro que uno de los objetivos del pensamiento crítico es la transformación de la realidad, comprenderla críticamente para actuar sobre ella. El materialismo histórico y el enfoque sistémico sirven a ambos autores, Wallerstein y Robinson, como enfoque teórico para el análisis de la evolución del modelo capitalista. Desde la teoría de la globalización, en este mismo capítulo, Robinson (2015) aporta una nueva construcción conceptual-propositiva para abordar el complejo momento histórico actual, a partir de postulados críticos que hacen reflexionar de manera objetiva desde nuestra subjetividad cotidiana, según las diferentes dimensiones de la globalización:

- Económica: La división global del trabajo se superpone a una división internacional del trabajo propia de la economía capitalista, con una estructura muy sesgada en la distribución del ingreso, que polariza y agrava las desigualdades sociales. 
URL: http://www.revistas.una.ac.cr/index.php/dialogo/index

CORREO ELECTRÓNICO: universidadendialogo@una.cr

DOI: http://doi.org/10.15359/udre.9-2.7

- Política: La evolución de un Estado-nación hacia un Estado nacional, ${ }^{1}$ a partir de la proliferación de actores de carácter transnacional que controlan el escenario internacional, donde las reglas se escapan de sus funciones históricamente asignadas, pasa a convertirse en un Estado transnacional (ETN), que estimula los flujos de capital transnacional.

- Ambiental: El capitalismo como un sistema depredador a partir de las necesidades de reproducción del orden económico transnacional, que nos conduce a un holocausto ecológico y al límite mismo de la acumulación capitalista (López y Rivas, 2016).

- Social: Pobreza y desigualdad. Robinson cuestiona que el discurso dominante sobre la desigualdad global sea territorial, que es lo mismo que la desigualdad entre naciones en un sistema global. Por el contrario, el autor nos indica que la polarización global es menos territorial que social, y refuerza esta afirmación señalando que el «sur global» se dispersa cada vez más por el mundo, al igual que el «norte global», definiendo jerarquías sociales y desigualdades de tipo mundial, no nacional. De igual forma esta expresión globalizante define un patrón geográfico emergente, dando como resultado el aumento de la heterogeneidad de los mercados o las reservas de trabajo en cada localidad, desde mano de obra muy calificada a obreros con bajo nivel educativo, combinando centro-periferia en una misma localidad.

De forma complementaria a lo expuesto por Robinson, en este análisis se hace referencia a las fases de formación del Estado en América Latina, planteadas por Eduardo Pastrana y Rafael Castro (2015), las que relacionaremos con otras variables, como la evolución de la institución de la educación superior universitaria de carácter estatal y sus constructos sociales, la autonomía universitaria y la libertad de cátedra, en una etapa actual del desarrollo del Estado, en medio del fenómeno de la globalización, según la caracterización planteada por Robinson.

\footnotetext{
Transnacionalización del Estado: La globalización no produce el fin del Estado-nación, sino su transformación en estados nacionales neoliberales. «¿Cómo funciona el universo del capital referido a la forma de Estadonación en nuestra era del capitalismo global?», pregunta Žižek. A la inversa, el papel del Estado neoliberal es servir a la acumulación de capital global (sobre lo local), incluyendo un cambio en los subsidios que proporcionan los Estados, separado de la reproducción social y de los agentes económicos internos y dirigido al capital transnacional. Estos Estados neoliberales realizan tres servicios esenciales: 1) Adoptar políticas fiscales y monetarias que garanticen la estabilidad macroeconómica; 2) proporcionar la infraestructura básica necesaria para la actividad económica global (puertos y aeropuertos, redes de comunicación, sistemas educativos, etc.); y 3 ) proveer orden social, es decir, estabilidad, lo que requiere instrumentos que mantengan el control social, aparatos coercitivos e ideológicos (Robinson, 2015, pp. 53-54).
} 
Revista Universidad en Diálogo • Vol. 9, N. ํㅡㄹ Julio-Diciembre, 2019 • 129-159

ISSN 2215-2849 • EISSN: 2215-4752

URL: http://www.revistas.una.ac.cr/index.php/dialogo/index CORREO ELECTRÓNICO: universidadendialogo@una.cr DOI: http://doi.org/10.15359/udre.9-2.7

Robinson (2015) presenta un gran desafío en materia de análisis de la realidad latinoamericana actual, al señalar que «el reto teórico es preguntarse ¿cómo y por quién son producidos los valores en el sistema capitalista mundial (organizados a través de instituciones), ¿cómo se los apropian? (a través de cuáles instituciones) y ¿cómo están cambiando estos procesos con la globalización capitalista?» (p. 62).

Además, agrega el autor, «necesitamos herramientas para conceptualizar, analizar y teorizar cómo esta presión expansiva inherente al sistema capitalista se manifiesta en la era de la globalización» $(2015$, p. 61).

En este sentido, podemos encontrar diferentes perspectivas sobre los temas de la autonomía y la libertad de cátedra en las universidades públicas en el contexto de la globalización, que algunos autores como Serrano y González consideran un epifenómeno ${ }^{2}$ frente al Estado. Otros estudiosos develan relaciones más complejas de las instituciones universitarias en relación con fenómenos diversos de la globalización, como las conocidas sociedades del conocimiento, que presentan un desafío a las tradicionales formas de educación y generación de conocimiento a nivel universitario, entre otras expresiones complejas, como la internacionalización de las universidades en el contexto global y actores con quienes interactúan, como las redes interinstitucionales de carácter transnacional o global.

Autores como Imanol Ordorika analizan las relaciones de fuerza dentro de un enfoque centro-periferia, derivadas de la globalización, tanto en el espacio nacional como en el internacional, y cómo se da el intercambio de estos fenómenos en la educación universitaria a nivel mundial, destacando el modelo hegemónico de educación superior. Ordorika considera que este fenómeno está «basado en una idealización del modelo norteamericano de universidades elitistas de investigación, que subordina y pone en cuestión a diversas tradiciones universitarias en distintas regiones y naciones» (2006, p. 2).

Ya desde 1997, Comboni y Juárez advertían de condiciones que el contexto marcaba a las universidades públicas, tales como,

La multiplicación de clientelas, la competencia de otras instancias de saber y formación, la presión de la lógica comercial y empresarial, las demandas de mayor transparencia pública, el aumento del ritmo y del costo de la renovación de conocimientos, son algunos de los temas que se agregan a otros viejos y conocidos asuntos pendientes de resolución. (p. 5)

2 Etimológicamente,fenómenoaccesorioqueacompañaalfenómenoprincipalyquenotieneinfluenciasobreél (Real Academia Española. Recuperado de http://dle.rae.es/srv/search?m=30\&w=epifen\%C3\%B3meno). 
De manera específica, más allá de tratar de responder a los sugerentes cuestionamientos de Robinson, el problema de estudio de este artículo pretende abordar estas interrogantes: ¿Qué significa la reforma de Córdoba en materia de autonomía universitaria y libertad de cátedra, considerando el contexto actual de dinámicas complejas y diversidad de actores de carácter global que superan el tradicional espacio de lo nacional y lo territorial, donde originalmente surgen estas reivindicaciones sociales? ¿Siguen siendo pertinentes en el siglo XXI las reivindicaciones logradas con la Reforma de Córdoba de 1918?

Por tanto, las siguientes secciones de este artículo tratan de responder a estas interrogantes, analizando el rol del Estado en su evolución y relación con las universidades públicas, la autonomía y la libertad de cátedra como constructos sociales en el marco del globalismo económico, las amenazas y los retos para la autonomía universitaria frente a los procesos de globalización y los cambios institucionales urgentes en la educación universitaria al día de hoy.

\section{Metodología}

Este artículo comprende el análisis de datos y documentos de descripción cualitativa que permiten interpretar la evolución de los dispositivos institucionales universitarios, la autonomía y libertad de cátedra, en la lógica actual de los procesos de globalización capitalista.

Esto implica la revisión exhaustiva de material bibliográfico procedente de fuentes secundarias y algunas fuentes primarias, que fundamente las argumentaciones teóricas de referencia, de tipo descriptivo. La principal fuente de información son los documentos generados por estudiosos de las instituciones de educación superior universitaria en América Latina. Gran parte de la información necesaria para dar respuesta a las principales interrogantes de este estudio es generada por este grupo de académicos.

\section{El Estado y las universidades públicas}

Para caracterizar la evolución del Estado, William Robinson (2017) identifica los sucesivos ciclos de acumulación del capitalismo, donde cada inserción se encuentra «fuertemente disputada entre fuerzas sociales y políticas». Estos ciclos o períodos van desde la conquista a la globalización, mientras que Pastrana y Castro (2015) nos hablan de periodos que cambian el rol del Estado, según características históricas particulares de los actores protagonistas y sus relaciones de fuerza. A continuación, se presenta una relación entre los ciclos de evolución capitalista, en relación con el Estado y las universidades públicas. 


\section{Un Estado en evolución}

Primer ciclo, denominado capitalismo mercantil, que promueve la acumulación primaria, este ciclo comprende procesos y eventos como la conquista, la incorporación violenta y la consolidación del sistema mercantil colonial (1492-1789).

En relación con las universidades en América Latina en este primer ciclo, Norma Giarraca apunta:

La primera universidad de América Latina, la Universidad Mayor de San Marcos, se creó en el siglo XVI, pero fue durante los siglos XVII y XIX cuando este tipo de centros adquirió una importancia significativa para la formación de las élites de los procesos independentistas y de consolidación nacional. (citada por De Sousa, 2007, p. 11)

Segundo ciclo, denominado como el industrial-competitivo (1789-1890): el cual comprendió la independencia criolla, las guerras civiles, las revoluciones liberales, una mayor inserción al mercado mundial, la extensión de capital, una vasta expansión de exportaciones de materia prima para la economía mundial (ejemplo, café, banano, guano, nitratos, azúcar, índigo, cacao).

En esta segunda fase, denominada por Pastrana y Castro (2015) como postcolonial, Tünnermann nos explica el rol histórico de las universidades,

Si bien el siglo XVII fue el más fecundo en cuanto al número de fundaciones, la decadencia de la Universidad colonial se inicia en este siglo y se acentúa en la primera mitad del siglo siguiente, hasta llegar a una verdadera postración académica, de la cual sólo las ansias de saber que trajo consigo la Ilustración pudo levantarla hacia fines del siglo XVIII. Igual postración experimentaron también en ese periodo las universidades de la metrópoli. Al referirse a la situación de las universidades españolas en el siglo XVIII, Altamira destaca el predominio de un sistema libresco, memorista, cuyo espíritu estrecho no era propicio para estimular la investigación científica, congelando el saber en simples fórmulas tradicionales. Sin embargo, el impacto de la Ilustración no fue igual en todas ellas. Varias continuaron viviendo dentro de los mismos esquemas hasta bien entrado el siglo XIX y aún después de la Independencia, por lo que fueron «coloniales fuera de la colonia». Con todo, esta segunda etapa es la que abarca el período más amplio de la colonia y es la que mejor representa el modo de ser, 
cometidos y quehacer de la universidad colonial De ahí que la mayoría de los juicios sobre ella se refieren principalmente a este período de su existencia, no obstante que para muchos historiadores la «edad de oro» de la colonia fue el XVIII (R.Konetzke, entre otros). (1991, p. 63)

Tercer ciclo, denominado "corporativo-monopólico», «fordista-keynesiano» (1890-1970): se da una nueva inserción capitalista, aparecen en América Latina importantes explicaciones teóricas sobre la división internacional del trabajo y las ventajas comparativas, como la de Raúl Prebish y su teoría del estructuralismo o dependencia, la expansión de los mercados nacionales, etc., surgen corrientes como el populismo, el corporativismo, el reformismo, la hegemonía disputada de viejas oligarquías, nuevas élites y clases populares que generan eventos como la Revolución mexicana, el peronismo en Argentina, Lázaro Cárdenas (México), Salvador Allende en Chile, la Alianza Popular Revolucionaria Americana (APRA) en Perú, Jacobo Árbenz Guzmán en Guatemala, José María Figueres Ferrer en Costa Rica.

A inicios del siglo XX, el comportamiento de las entidades de educación superior universitaria es caracterizado por Giarraca, citada por De Sousa (2007), de la siguiente manera,

A comienzos del siglo XX, varias instituciones latinoamericanas protagonizaron un proceso de democratización y reforma que acompañó al surgimiento y protagonismo de los sectores medios en estas nuevas sociedades. El Manifiesto de Córdoba, la culta provincia mediterránea de la Argentina, escrito por la «Juventud argentina de Córdoba a los hombres libres de Sudamérica», en junio de 1918, comienza con un llamado a la «república libre», apelando a borrar las ataduras de la dominación monárquica y monástica y a conquistar las libertades aún no conseguidas. Es el comienzo -anuncia- de una revolución, el momento de empezar a vivir «una hora americana». (p. 11)

Continúa la autora con el análisis de la evolución de la institucionalidad universitaria durante el siglo XX así,

Mientras se consolidaba un modelo de universidad basado en el conocimiento disciplinar y -como señala Santos- con un proceso de producción relativamente descontextualizado en relación con la sociedad, la mayoría de los estudiantes luchaba por un acceso democrático y por establecer articulaciones fructíferas con la comunidad. La universidad conseguida - de excelencia, pero aislada-, así como las sociedades 
Revista Universidad en Diálogo • Vol. 9, N. ${ }^{\circ} 2$, Julio-Diciembre, 2019 • 129-159

ISSN 2215-2849 • EISSN: 2215-4752

URL: http://www.revistas.una.ac.cr/index.php/dialogo/index CorReo ElECtrónico: universidadendialogo@una.cr DOI: http://doi.org/10.15359/udre.9-2.7

receptoras -desiguales, pero aún con mecanismos de integración-, desde fines de los setenta, mutaron en los escenarios de esta globalización de economías abiertas y sociedades excluyentes. Tanto los estados nacionales como las universidades fueron fuertemente estigmatizados y el «mercado», como mecanismo y como dispositivo ideológico, apareció como alternativa y «única salida». (Giarraca, citada por De Sousa, 2007, p. 11)

El cuarto ciclo (1980-1990), se da con la crisis del capitalismo, del Estadonación, la globalización ${ }^{3}$ conduce a un periodo de crisis y cambio social en América Latina, buscando nuevas formas de inserción del capitalismo mundial. ${ }^{4}$ Pastrana y Castro llaman a esta fase hegemónica o post Guerra Fría.

Boaventura de Sousa explica lo siguiente en relación con este proceso de ajuste institucional,

3 Neoliberalismo global: El modelo para la reestructuración global descansa en los supuestos de la economía neoclásica que eclipsó al keynesianismo y trajo un conjunto particular de políticas sociales y económicas conocidas como neoliberalismo. La economía neoclásica, con su doctrina de laissezfaire, de las ventajas comparativas, el libre comercio y la eficiencia, se convirtió en hegemónica en las universidades y los Gobiernos de todo el Primer Mundo. El razonamiento teórico del neoliberalismo fue esbozado por primera vez por Friedrich Hayek y la escuela austriaca de economía, y más tarde perfeccionado por Milton Friedman y otros economistas neoclásicos de la escuela monetarista de la Universidad de Chicago (los Chicago Boys). Fue implementado experimentalmente en Chile tras el golpe de Estado de 1973, que dio el poder a la dictadura de Augusto Pinochet. Pero fueron los gobiernos de Ronald Reagan, en Estados Unidos (1981-1989), y de Margaret Thatcher, en el Reino Unido (19791990), los que catapultaron al neoliberalismo al centro de la escena del capitalismo mundial, y las instituciones financieras internacionales (IFI), como el Fondo Monetario Internacional y el Banco Mundial, las que impusieron el modelo en gran parte del Tercer Mundo en las décadas de 1980 y 1990 a través de programas de ajuste estructural, en lo que llegó a ser conocido como el Consenso de Washington (Williamson, 1990, 1993; Gore, 2000, citado por Robinson, 2015, pp. 37-38). El neoliberalismo, en pleno apogeo en la década de 1990, se había convertido en dominante no solo en las IFI, sino en la mayoría de los organismos internacionales y las organizaciones intergubernamentales, incluyendo foros como la Organización de Estados Americanos (OEA) y la Organización para la Cooperación y el Desarrollo Económicos (OCDE), y los organismos técnicos de las Naciones Unidas como la Organización Mundial de la Salud (OMS), la organización de las Naciones Unidas para la Alimentación y la Agricultura y el Fondo de las Naciones Unidas para la Infancia (Robinson, 2015, pp. 37-38).

4 Robinson (2017) amplía características de esta nueva ronda expansiva del capitalismo en la región. Los tres rasgos de la globalización en América Latina: 1) Producción transnacional; 2) clase capitalista transnacional; y 3) transnacionalización del Estado; sobre seis nuevos ejes de acumulación: (1) Reconversión industrial: maquiladora e industria subcontratada (Fábrica global); (2) exportaciones agrícolas no tradicionales, fruta, verduras, soya, palma africana, flores, especies, maricultura, biocombustibles, etc., más Flexicosechas (Finca/supermercado global); (3) Turismo global (Ruta Maya, San Juan del Sur, Ruta Inca, ecoturismo, etc.); (4) Servicios y finanzas transnacionales (call centers, banca, malls, etc.); (5) exportación de mano de obra, importación de remesas, mercado global de trabajo; (6) expansión extractivista de minería, exportaciones de materia prima (energética, oro, litio, etc.). 
URL: http://www.revistas.una.ac.cr/index.php/dialogo/index

CORREO ELECTRÓNICO: universidadendialogo@una.cr

DOI: http://doi.org/10.15359/udre.9-2.7

La pérdida de prioridad de la universidad pública en las políticas públicas del Estado fue, ante todo, el resultado de la pérdida general de prioridad de las políticas sociales (educación, salud, seguridad social) inducida por el modelo de desarrollo económico conocido como neoliberalismo o globalización neoliberal, que se impuso internacionalmente a partir de la década de los 80 . En la universidad pública esto significó, que las debilidades institucionales antes identificadas -que no eran pocas- en vez de servir para un amplio programa político pedagógico de reforma de la universidad pública, fueron declaradas insuperables y utilizadas para justificar la apertura generalizada del bien público universitario para la explotación comercial. A pesar de las declaraciones políticas contrarias y de algunos gestos reformistas, subyace a este primer embate del neoliberalismo la idea de que la universidad pública es irreformable (así como lo es el Estado) y que la verdadera alternativa está en la creación del mercado universitario. El modo salvaje y desregulado como emergió y se desarrolló este mercado, es la prueba de que había en su favor una opción de fondo. Y la misma opción explicó la descapitalización y desestructuración de la universidad pública en favor del emergente mercado universitario con transferencias de recursos humanos que algunas veces configuraron un marco de acumulación primitiva por parte del sector privado universitario a costa del sector público. (2007, p. 26)

Las universidades públicas de carácter estata ${ }^{5}$ dependen financieramente del Estado, de un Estado desarrollista que ha garantizado desde el tercer ciclo de acumulación capitalista su existencia y su financiamiento. Ese Estado se encuentra en pleno cambio, en el debate entre los sectores neoliberales que detentan el poder de la institucionalidad pública y sus recursos, así como de los sectores académicos que defienden la autonomía universitaria y la libertad de cátedra, aun cuando esta no se encuentre declarada constitucionalmente en sus contextos específicos.

\footnotetext{
En relación con el concepto de universidad pública estatal, hacemos referencia al planteamiento de De Sousa: «A lo largo de este texto, cuando me refiero a la universidad pública asumo su carácter estatal. Bresser Pereira, que fue Ministro de Ciencia y Tecnología y de Administración Federal y Reforma del Estado en el gobierno de Fernando Henrique Cardoso, fue uno de los más destacados defensores de la idea de universidad pública no-estatal. No es aquí el lugar para hacer una crítica detallada a esta propuesta; pero diré solamente que además de ser poco probable que se pueda adoptar con éxito el modelo de las universidades norteamericanas en un contexto semiperiférico, esta propuesta contiene varios riesgos: asume el fin de la gratuidad de la enseñanza pública; profundiza la desvinculación del Estado en relación con la universidad pública, ya que el Estado deja de ser su financiador exclusivo; aumenta y desregula la competencia entre la universidad pública y la universidad privada y como ésta, al contrario de lo que pasa en Estados Unidos, es de calidad inferior a la universidad pública, es natural que la nivelación se dé hacia abajo» (De Sousa, 2007, p. 51, Cita 26).
} 
Revista Universidad en Diálogo • Vol. 9, N. 2 2, Julio-Diciembre, 2019 • 129-159

ISSN 2215-2849 • EISSN: 2215-4752

URL: http://www.revistas.una.ac.cr/index.php/dialogo/index CorReo ElECtrónico: universidadendialogo@una.cr

DOI: http://doi.org/10.15359/udre.9-2.7

Tal como plantea Robinson (2015) en relación con el rol del Estado desarrollista, el capitalismo corporativo como capitalismo keynesiano se reorganizó en torno a un nuevo modelo de estructura social de acumulación, convirtiéndose en un nuevo pacto capitalista o capitalismo de bienestar. Este Estado de bienestar o interventor busca la creación de crédito, empleo y política fiscal progresiva que permitiera el gasto gubernamental en obras públicas y programas sociales. Esta tríada entre la macroeconomía keynesiana, el régimen de acumulación fordista y la propuesta de programa de bienestar para lograr la reproducción social permite la existencia del Estado-nación. Robinson analiza los cambios de esta forma de Estado y plantea que con la reestructuración del Estadonación hacia formas de sociedad globalizada crece la desigualdad social y se reduce la cohesión social, producto de la dialéctica entre las estructuras históricamente determinadas y las nuevas estructuras transnacionales. ${ }^{6}$

El Estado nacional, según Robinson (2015), se centra en el Gobierno, mismo que facilita el accionar de los agentes transnacionales capitalistas, generando relaciones transnacionales que permiten «superar la crisis de capitales». Esta se empieza a perfilar a partir de la crisis 1970, lo que significó la desaceleración económica mundial, poniendo al capitalismo competitivo industrial en crisis. Esto obliga a los agentes capitalistas transnacionales a redefinir el rol del Estado-nación ${ }^{7}$ en Estado nacional, para poder cumplir un rol fundamental en la nueva configuración del poder global, al apoyar los cambios globales en las relaciones de poder entre las clases y los grupos sociales, propios del modelo anterior de Estado-nación. Robinson (2015) identifica al líder de esta transformación de forma presente y futura como el Gobierno de los Estados Unidos de América, que cumple el papel de reorganizador del capitalismo. Continuando con el planteamiento de Robinson (2015), este nuevo orden, basado en su hegemonía (de tipo coercitiva), supera el enfoque del imperialismo basado en la existencia de economías nacionales y capitales nacionales, reconociendo la existencia de grupos que ejercen el poder social

\footnotetext{
La globalización como cuarta época de capitalismo mundial está marcada por una serie de cambios fundamentales en el sistema, incluyendo:1) El aumento del capital verdaderamente transnacional y un nuevo sistema globalmente integrado de producción y finanzas; 2) la transnacionalización de las clases y el surgimiento de una clase capitalista transnacional como clase hegemónica en todo el mundo; 3) el surgimiento de un aparato de Estado transnacional; 4) nuevas relaciones de poder y desigualdad en la sociedad global (Robinson, 2015, p. 45).

7 La continua división del mundo en Estados-nación constituye una condición fundamental para el poder del capital transnacional porque los Estados-nación solo pueden ejercer su jurisdicción/soberanía dentro de sus fronteras nacionales, en cambio el capital transnacional opera más allá de las fronteras nacionales y, por lo tanto, no está regulado ni responde a ninguna autoridad política única (Robinson, 2015, pp. 56-57).
} 
a través de instituciones que controlan la producción de valor, la apropiación de excedentes y la reproducción de este nuevo orden transnacional, que ya no reconoce la división internacional del trabajo, sino la división global del trabajo. Este capitalismo corporativo genera la rearticulación a nivel local, nacional y regional, consolidando los estados neoliberales ${ }^{8}$ como promotores del modelo transnacional de acumulación.

De Sousa (2007), relacionando al Estado con la universidad pública, hace un relevante señalamiento,

La universidad es un bien público íntimamente ligado al proyecto de nación. El sentido público y cultural de este proyecto y su viabilidad, dependen de la capacidad nacional para negociar de manera calificada, la inserción de la universidad en los contextos de transnacionalización. En el caso de la universidad y de la educación en general, esa cualificación es la condición necesaria para no transformar la negociación en un acto de rendición y con él, el fin de la universidad tal como la conocemos. No habrá rendición si existen condiciones para una globalización solidaria y cooperativa de la universidad. Porque los aliados son pocos y los intereses hostiles al florecimiento de la universidad pública tienen hoy mucho poder en el interior del Estado, que bajo la forma de actores mercantiles nacionales y transnacionales, bajo la forma de agencias internacionales al servicio de unos y de otros, la reforma de la universidad como bien público tiene un significado que trasciende a la universidad. Como procuré demostrar, la universidad en tanto bien público es hoy un campo de enorme disputa. Más o menos lo mismo sucede con el Estado. La dirección que tome la reforma de la universidad será la dirección que tome la reforma del Estado. De hecho, la disputa es una sola, algo que los universitarios y los responsables políticos deben tener siempre presente. (p. 94)

De ahí el peligro de la desaparición del Estado-nación para las universidades públicas de carácter estatal. En este sentido, el senador y académico de la Universidad de Chile, el profesor Rodrigo Baño, reflexiona sobre el tema,

La Universidad de Chile se define como una universidad pública. El problema de su confusión con universidades privadas deriva del hecho de que ha sido despojada cada vez más de su carácter público. Forzada al autofinanciamiento, ha tenido que optar por vender en el mercado su

\footnotetext{
A la inversa el papel del Estado neoliberal es servir a la acumulación de capital global (sobre lo local), incluyendo un cambio en los subsidios que proporcionan los Estados, separado de la reproducción social y de los agentes económicos internos y dirigido al capital transnacional (Robinson, 2015, p. 53).
} 
docencia, con lo cual no aparece respondiendo al derecho a la educación de los ciudadanos, sino como un oferente ante la demanda de estudios con poder de compra, sea al contado, con crédito o con subsidio estatal. Sus investigaciones se financian con proyectos que instituciones externas definen como prioritarios o directamente con venta de estudios de interés privado. Su extensión se limita cada vez más por falta de recursos y tiene que recurrir al interesado aporte privado y a vender sus producciones. $(2017$, s. p.)

Como corolario de estos planteamientos, puede concluirse que la relación entre el Estado y las universidades públicas resulta siempre política y con tensiones, razón por la cual la tan defendida autonomía y la libertad de cátedra no sería posible si de alguna forma el pacto social entre universidades públicas y Estado no correspondiera a alguna seguridad normativa o jurídica, que defienda el funcionamiento de estas por medio de presupuestos significativos en sus gastos totales. En el caso de la Universidad de Chile, el presupuesto asignado es de apenas el $14 \%$ de sus gastos totales, lo que la pone en una relación de desventaja en términos de autonomía y operación institucional con otras universidades públicas en América Latina (Baño, 2017).

\section{La Reforma de Córdoba: origen de la autonomía y la libertad de cátedra universitaria en el contexto latinoamericano}

La autonomía como constructo social y la libertad de cátedra como derecho universal son una expresión del imaginario de la sociedad académica, desarrollado a través del tiempo. ${ }^{9}$ Desde inicios del siglo XX, en el denominado tercer ciclo de inserción y acumulación del capitalismo, según William Robinson, caracterizado por ser un momento histórico mundial con grandes eventos tensionales del modelo capitalista, tales como la Revolución mexicana de 1910, la Revolución rusa de 1917 y el enfrentamiento entre las grandes potencias hegemónicas en la Primera Guerra Mundial en la primera mitad del siglo XX, sucede un acontecimiento en la región latinoamericana, un importante evento que revolucionó a las universidades públicas en el marco de la reivindicación de otro derecho, la insurrección popular, dirigida por la militancia estudiantil y académica de la Universidad de Córdoba, Argentina. El cuestionamiento polí-

\footnotetext{
Barboza, citado por Andrés León (2012, p. 2): «El primer intento en Latinoamérica por hacer la universidad democrática, con autonomía, financiada por el Estado y abierta a todas las clases sociales fue en 1827 cuando Simón Bolívar promulgó los Estatutos Universitarios Republicanos, pero después, como con casi toda la obra de El Libertador, fueron completamente desvirtuados sus postulados y dejados en el olvido (citado por Barbosa, 2010 en León, 2012, p. 2).
} 
URL: http://www.revistas.una.ac.cr/index.php/dialogo/index

CORREO ELECTRÓNICO: universidadendialogo@una.cr

DOI: http://doi.org/10.15359/udre.9-2.7

tico-social a un modelo universitario creado en 1613, heredado de la colonia, conocido como modelo napoleónico, es la respuesta activa y reivindicativa en un contexto de huelgas constantes de la clase trabajadora, frente a un régimen político oligárquico-conservador que «daba lugar a la primera apertura electoral a través de la Ley de Roque Sáenz Peña que llevó a la elección de Hipólito Yrigoyen en 1916». ${ }^{10}$ En este contexto histórico argentino, el estudiantado cordobés comenzó a exigir la creación de reformas universitarias, pues esta venía operando al mejor estilo de los tiempos coloniales. Tal como nos narra Oñativia, a inicios del siglo XX «las ideas darwinistas eran consideradas heréticas y se impartían materias como la de "Deberes para con los siervos"》 (2016, p. 1).

Estos grupos adversarios de la tradicional clase dirigente de las universidades públicas de Argentina logran el reconocimiento de la gran Reforma de Córdoba en 1918, cuyo legado adoptó un carácter universal y una instrumentalización institucional, no solo en América Latina, sino a nivel mundial, a pesar de que en muchas universidades europeas la libertad de cátedra era reconocida desde siglos anteriores en instituciones académicas. ${ }^{11}$ Plantea Hernández

10 El argentino Fabio Oñativia escribe en La Izquierda Diario: «La Reforma Universitaria de 1918 en Argentina. ¿Qué fue la Reforma Universitaria?» donde presenta una síntesis del movimiento reformista de 1918, que revolucionó las universidades latinoamericanas.

11 Carta de Derechos Fundamentales de la Unión Europea: artículo 13; libertad de las artes y de las ciencias: las artes y la investigación científica son libres. Se respeta la libertad de cátedra. Constitución Española: artículo 20; 1 . Se reconocen y protegen los derechos: [...] c) A la libertad de cátedra [...]. Definición de libertad de cátedra: 1. Facultad que ostenta todo docente universitario de transmitir sus conocimientos como considere oportuno, con independencia de que provengan, o no, de su propia labor investigadora. Es un derecho particular frente al Estado. 2. Se manifiesta en el ejercicio del derecho del profesorado universitario a expresar libremente, en el desarrollo de su actividad docente, sus ideas y convicciones científicas, técnicas culturales y artísticas. 3. Libertad de elección del profesorado universitario del planteamiento teórico y del método, sin más límites que los establecidos en la Constitución y en las leyes y los derivados de la organización de las enseñanzas de la Universidad. 4. Tribunal Constitucional: [...] Derecho fundamental -como libertad individual del docente- es una proyección de la libertad ideológica y del derecho a difundir libremente los pensamientos, ideas y opiniones, que cada profesor asume como propias en relación con la materia objeto de su enseñanza [...]. 5. Ley Orgánica de Universidades: la docencia es un derecho y un deber de los profesores de las Universidades que ejercerán con libertad de cátedra, sin más límites que los establecidos en la Constitución y en las leyes y los derivados de la organización de las enseñanzas en sus universidades. 6. UNESCO: El personal docente de la enseñanza superior tiene derecho al mantenimiento de la libertad académica, es decir, la libertad de enseñar y debatir sin verse limitado por doctrinas instituidas (libertad de cátedra), la libertad de llevar a cabo investigaciones y difundir y publicar los resultados de las mismas, la libertad de expresar libremente su opinión sobre la institución o el sistema en que trabaja, la libertad ante la censura institucional y la libertad de participar en órganos profesionales u organizaciones académicas representativas. Todo el personal docente de la enseñanza superior debe poder ejercer sus funciones $\sin$ sufrir discriminación alguna y sin temor a represión por parte del Estado o de cualquier otra instancia. Link UNESCO. Recuperado de http://deim.urv.cat/ blas.herrera/catedra.html 
Revista Universidad en Diálogo • Vol. 9, N. ํㅡㄹ Julio-Diciembre, 2019 • 129-159

ISSN 2215-2849 • EISSN: 2215-4752

URL: http://www.revistas.una.ac.cr/index.php/dialogo/index CoRreo ElECtrónico: universidadendialogo@una.cr DOI: http://doi.org/10.15359/udre.9-2.7

(1985) que la libertad de cátedra como libertad civil o pública se reconoce constitucionalmente por primera vez en Alemania, es decir, constituye una herencia de la universidad alemana del siglo XIX. En América Latina este derecho se introduce con la Reforma de la Universidad de Córdoba (universidad de Argentina), promovida por los estudiantes y con el apoyo de algunos miembros del personal docente, que en esos momentos en su mayoría eran fieles representantes de los sectores dominantes y de los mismos intereses colonialistas que aún persistían. Así progresivamente, en las diferentes universidades de América Latina, este derecho se ha reafirmado o, por otro lado, se ha violado, hasta el punto de causar muertes a educadores que no comparten el pensamiento de las clases gobernantes (tal es el caso de las universidades de Chile, Guatemala y El Salvador en la década de los ochenta).

En relación con los derechos humanos, esta libertad de cátedra ha generado un debate sobre su norma, Hernández cita al respecto,

Para enmarcar la libertad de cátedra dentro de las libertades civiles, retomamos el pensamiento de John Brubacher, profesor de enseñanza superior en el Centro para el Estudio de la Enseñanza Superior, de la Universidad de Michigan: «En la búsqueda interminable de la verdad, el profesor no sólo está armado con su libertad académica sino también con las libertades civiles. Sin embargo, se debe distinguir con cuidado a los dos (Searle, 1972, pp. 92-93; Van Alstyne, 1972, p.70; Jaspers, 1959, p. 132). Las libertades civiles, de acuerdo con Searle, son las más generales de las dos. Suponen que la libertad individual es deseable para todos los ciudadanos de una democracia. En contraste, la libertad académica es un caso especial de libertad, aplicable solo a la comunidad de estudiosos. Las libertades civiles se derivan de los principales principios políticos, en tanto que la libertad académica se deriva de la naturaleza del aprendizaje superior. Ya se ha observado que la Suprema Corte de los Estados Unidos encontró lugar para la libertad académica bajo la Primera Enmienda (Sweezey vs. New Hampshire, 1957). De cualquier modo, los profesores son miembros de las dos entidades políticas: civil y académica. ¿Cuándo deben defenderse sus opiniones probablemente impopulares con sus libertades civiles y cuándo con su libertad académica? Generalmente invocan a la libertad académica cuando hablan o escriben dentro de sus propios campos de acción, y a las libertades civiles cuando las opiniones que expresan se quedan fuera de sus «cátedras». (1985, p. 74). 
URL: http://www.revistas.una.ac.cr/index.php/dialogo/index

CORREO ELECTRÓNICO: universidadendialogo@una.cr

DOI: http://doi.org/10.15359/udre.9-2.7

Por otro lado, en relación con la autonomía en el contexto de la Reforma de Córdoba, Tünnermann señala,

El concepto de autonomía sustentado por el movimiento reformista era muy amplio: implicaba el reconocimiento del derecho de la comunidad universitaria a elegir sus propias autoridades, sin interferencias extrañas; la libertad de cátedra; la designación de los profesores mediante procedimientos puramente académicos que garantizaran su idoneidad; la dirección y gobierno de la institución por sus propios órganos directivos; la aprobación de planes y programas de estudio; elaboración y aprobación del presupuesto universitario, etcétera. Incluso se llegó a recomendar la búsqueda de un mecanismo que permitiera a la universidad su autofinanciamiento (autarquía patrimonial) con el fin de evitar las presiones económicas por parte del Estado, o de las otras fuentes de ingresos, que en determinado momento podían hacer irrisoria la autonomía formal. Más tarde, y ante las constantes amenazas de parte de las fuerzas públicas, se incluyó la inviolabilidad de los recintos universitarios, de reconocido abolengo medieval. Con esto, el concepto de autonomía adquirió características que, en ese momento, no existían en otras partes del mundo. Seguramente, al movimiento reformista se debe el énfasis puesto en este aspecto de la vida universitaria latinoamericana, cuya necesidad e importancia para el desarrollo universitario y social del continente ha quedado plenamente demostrada. $(2008$, p. 7$)$

La tensión original entre Estado-universidad, que dio inicio a la Reforma de Córdoba, como revuelta histórica, es mediada de esta forma por la instrumentalización del principio de autonomía universitaria y sus derivaciones normativas, que adquieren variadas formas, entre estas la libertad de cátedra.

\section{Para Tünnermann, ${ }^{12}$}

La llamada Reforma de Córdoba de 1918 fue el primer cuestionario a fondo de nuestras universidades y señala el momento histórico del ingreso de América Latina en el siglo XX y del ascenso de las clases medias urbanas que, en definitiva, fueron las protagonistas del Movimiento. (2005, p. 8)

\footnotetext{
Carlos Tünnermann Bernheim, primer secretario general del CSUCA, exministro de Educación de Nicaragua y académico de la UCA en su ponencia La autonomía universitaria frente al mundo en el encuentro de la Unión de Universidades de América celebrado en Santo Domingo, República Dominicana, 24 de noviembre de 2005. Este autor es además especialista centroamericano en materia de educación superior, ha escrito varias obras fundamentales para el análisis de la autonomía universitaria, donde hace análisis de procesos históricos y epistemológicos.
} 
Revista Universidad en Diálogo • Vol. 9, N. 2 2, Julio-Diciembre, 2019 • 129-159

ISSN 2215-2849 • EISSN: 2215-4752

URL: http://www.revistas.una.ac.cr/index.php/dialogo/index CorReo ElECTRÓNICO: universidadendialogo@una.cr DOI: http://doi.org/10.15359/udre.9-2.7

Mientras que en el prefacio de la obra de Boaventura de Sousa (2007) se rescata que fue un acto de resistencia que buscaba articulaciones democráticas entre universidad-sociedad, frente a las expresiones diversas de la dominación de los territorios argentinos, durante el siglo XX y frente a un proceso fuera de lugar histórico en relación con el desarrollo intelectual de la sociedad académica emergente.

\section{Amenazas de la globalización para la autonomía universitaria y libertad de cátedra}

Carlos Tünnermann escribió en el 2005, en varias de sus publicaciones sobre universidades, educación superior y globalización, que una de las mayores amenazas para las universidades públicas es el Acuerdo General de Comercio de Servicios (GATS, por su sigla en inglés), cuyo mayor opositor en la implementación al interior de la OMC ha sido el bloque de los BRICS (Brasil, Rusia, India, China y Sudáfrica), por tanto nuevas iniciativas han retomado su espíritu hoy día en lo que se conoce como los tratados de nueva generación que contemplan una relación bilateral o regional, tal es el caso del Trade in Services Agreement (TISA) ${ }^{13}$ o Acuerdo sobre el Comercio de Servicios (ACS). En relación con el GATS, Tünnermann reflexiona de manera específica sobre su amenaza para la educación superior pública,

El riesgo mayor proviene, en estos momentos, de la resolución adoptada en el año 2002 por la Organización Mundial de Comercio (OMC), de incluir la educación superior como un servicio comercial regulado en el marco del Acuerdo General de Comercio de Servicios (GATS, por su sigla en inglés), decisión que han impugnado, entre otros organismos, la Asociación Internacional de Universidades (AIU), la Unión de Universidades de América Latina (UDUAL), la Asociación de Universidades y Colegios de Canadá, la Asociación de Universidades Europeas, el American Council on Education, la Asociación de Universidades del Grupo de Montevideo, el Consejo Superior Universitario Centroamericano (CSUCA) y las Cumbres Iberoamericanas de Rectores de Universidades Públicas. (2005, p. 22.)

13 La historia del TISA comenzó en el año 2012 cuando dieciséis países decidieron constituirse como grupo promotor, bajo la llamativa denominación de Really Good Friends of Services (RGF), para impulsar la adopción de un nuevo tratado multilateral de servicios. Datos clave: se trata de un acuerdo para liberalizar el comercio de servicios. Participan veintitrés miembros de la Organización Mundial del Comercio (OMC), incluida la Unión Europea, que representan el 70\% del comercio mundial del sector. Está abierto a otros miembros de la OMC y es compatible con el acuerdo AGCS. Podría incluirse en la OMC tras la adhesión de un número suficiente de miembros. Hasta noviembre de 2016 se han mantenido veintiuna rondas de negociaciones en Ginebra. No hay un plazo establecido para poner fin a las negociaciones. Recuperado de http://ec.europa.eu/trade/policy/in-focus/tisa/index_es.htm 
URL: http://www.revistas.una.ac.cr/index.php/dialogo/index

CORREO ELECTRÓNICO: universidadendialogo@una.cr

DOI: http://doi.org/10.15359/udre.9-2.7

Por otro lado, William Robinson ${ }^{14}$ afirma que, si bien las fuerzas transnacionales pueden eliminar la existencia de las universidades públicas, estas de igual forma pueden sobrevivir en la lógica del capitalismo transnacional, al transformarse en instituciones útiles a la clase capitalista transnacional sin perder su condición de universidad pública. Estas exigencias de las IFI (Instituciones Financieras Internacionales), estilo el Banco Mundial o el Banco Interamericano de Desarrollo, que financian las universidades públicas, pueden conducir a la mercantilización de las universidades, convirtiéndolas en un servicio rentable, como propone la Organización Mundial del Comercio, sin privatizarlas, pero poniéndolas a competir con la denominada «sociedad del conocimiento», ${ }^{15}$ situación que las puede llevar a cambiar su proyección y acción en materia de compromiso social universitario, para generar conocimiento económicamente útil al servicio del mercado, especialmente en las áreas de investigación y docencia, tal como advierte Tünnermann (2005).

Las universidades públicas siguen siendo de igual forma entes que aspiran a la producción de conocimiento de excelencia (conocimiento científico, tecnológico o gerencial), ${ }^{16}$ pero ya no de forma hegemónica, pues, como señala Tünnermann, la «sociedad del conocimiento» es una amenaza, pues no responde a las necesidades de la sociedad, sino del mercado. José Joaquín Brunner

14 Comunicación personal de William Robinson. (10 de agosto de 2017). Universidad Nacional, Costa Rica.

15 «Una de las características de la sociedad contemporánea es el papel central del conocimiento en los procesos productivos, al punto que el calificativo más frecuente que suele dársele es el de sociedad del conocimiento. Asistimos a la emergencia de un nuevo paradigma económico-productivo en el cual el factor más importante no es ya la disponibilidad de capital, mano de obra, materias primas o energía, sino el uso intensivo del conocimiento y la información. Las economías más avanzadas hoy día se basan en la mayor disponibilidad de conocimiento. Las ventajas comparativas dependen cada vez más del uso competitivo del conocimiento y de las innovaciones tecnológicas. Esta centralidad hace del conocimiento un pilar fundamental de la riqueza y el poder de las naciones pero, a la vez, estimula la tendencia a su consideración como simple mercancía, sujeta a las reglas del mercado y susceptible de apropiación privada. Esta realidad no debe conducirnos a concebir la universidad como simple productora de "capital humano altamente calificado"» (Tünnermman, 2005, p.15).

16 La Declaración Mundial sobre la Educación Superior, citada por Tünnermmann (2005, p. 15), señala en su preámbulo que «si se carece de instituciones de educación superior e investigación adecuadas que formen una masa crítica de personas cualificadas y cultas, ningún país podrá garantizar un auténtico desarrollo endógeno y sostenible; los países en desarrollo y los países pobres, en particular, no podrán acortar la distancia que los separa de los países desarrollados industrializados». Y el artículo primero de la Declaración reafirma «la necesidad de preservar, reforzar y fomentar aún más las misiones y valores de la educación superior, en particular la misión de contribuir al desarrollo sostenible y el mejoramiento del conjunto de la sociedad». «La sociedad del conocimiento, dice a su vez la Declaración de Santo Domingo ("La ciencia para el siglo XXI"), (marzo, 1999), implica potenciar la capacidad tecnológica combinando formas tradicionales y modernas que estimulen la creación científica y hagan viable el desarrollo humano sostenible». 
(2010), del Centro de Políticas Comparadas de Educación de la Universidad Diego Portales de Chile, quien trabaja sus estudios sobre la contribución de las universidades al uso del conocimiento, a partir de metodologías de la Organización Económica para la Cooperación y el Desarrollo, ${ }^{17}$ señala algunos de esos criterios sobre la demanda de producción del conocimiento en una lógica de mercado. Los siguientes indicadores verifican la gestión del conocimiento reconocida por la OCDE:

- Creación del conocimiento (especialmente a través de la investigación)

- Desarrollo de capacidades (especialmente mediante docencia y formación de investigadores)

- Difusión y transferencia del conocimiento (mediante interacción con usuarios del conocimiento a través de diversas modalidades)

- Deliberación pública con base en conocimiento (reflexividad, diseño y evaluación de políticas públicas, crítica social)

A pesar de que la «sociedad del conocimiento» es considerada como una amenaza por autores como Tünnermann, vale la pena reflexionar sobre si es posible convertir una amenaza en oportunidad, al competir con otras universidades o instituciones en la generación de conocimiento, sin perder la dimensión normativa de la autonomía universitaria y la libertad de cátedra al servicio de la sociedad, como elementos esenciales de la capacidad institucional y del compromiso social de la educación universitaria pública en América Latina.

\section{Retos para la autonomía y libertad de cátedra de las universidades públicas}

Tal como plantea Boaventura de Sousa en relación con la identificación de los sujetos con quienes las universidades públicas de carácter estatal, deben superar lo que él llama la triple crisis, refiriéndose a la pérdida de hegemonía, legitimidad y crisis institucional,

Para identificar los sujetos, es necesario definir previamente el sentido político de la respuesta a tales desafíos. A la luz de lo precedente, se hace claro que a pesar de la multiplicidad de las causas de la crisis de la universidad y que algunas de ellas son de larga data, se están reconfigurando hoy en día por la globalización neoliberal y el modo como esta afecta hoy los designios. (2007, p. 51) 
URL: http://www.revistas.una.ac.cr/index.php/dialogo/index

CORREO ELECTRÓNICO: universidadendialogo@una.cr

DOI: http://doi.org/10.15359/udre.9-2.7

Dentro de esta misma lógica y citando a continuación a autores que han reflexionado profusamente sobre el tema, cabe la pregunta ¿qué tipo de modelo de universidad promueve la autonomía y la libertad de cátedra al día de hoy?

Tünnermann defiende un modelo de universidad: «La Universidad no puede renunciar a su misión de forjadora de una cultura de responsabilidad que va más allá de la simple función de formadora del capital intelectual del país» (2005, p. 15).

Para Humberto Tommasino, esta respuesta está sujeta al modelo que cada universidad de forma autónoma defina en su relación con la sociedad y el Estado. En este sentido, el autor uruguayo caracteriza estos modelos según la propuesta mercantilista, desarrollista o popular. ${ }^{18}$

Jacinto Ordóñez dialoga también en este sentido al afirmar:

Decía Martín-Baró que frente a las necesidades del pueblo se requiere de ciencia pero también de conciencia. El trabajo científico implica estudio, investigación y sacrificio; la conciencia implica romper con actitudes que impiden ver la complejidad de los problemas de nuestros pueblos, sus vínculos y sus consecuencias. Para lograrlo, se necesitaba, decía él, del «acompañamiento» de la Universidad con su propio pueblo. La falta de esta opción ética generaba una esquizofrenia que debía ser superada, la esquizofrenia de ser Universidad sostenida por el pueblo pero a la vez alejada de su realidad. (s. f., p. 9)

8 Modelo mercantilista: Formación de profesionales que el mercado demanda para el desarrollo capitalista nacional y la inserción periférica del país en el mercado mundial. Investigación en áreas determinadas por contrapartes industriales o empresariales. Es el mercado el que establece las áreas prioritarias de formación e investigación.

Enseñanza como función principal del modelo del voluntariado y la responsabilidad social empresarial. Modelo de las pasantías de capacitación en empresas u organismos del Estado. Modelo desarrollista: Formación de profesionales orientados a las áreas productivas que precisan dinamizarse de acuerdo con un proyecto de desarrollo nacional. Esto coexiste con la formación de profesionales para el mercado. Investigación e innovación para agregar conocimiento al sistema productivo nacional. Búsqueda de la articulación de las funciones universitarias, investigación, extensión y docencia. Modelo de universidad popular: Formación de universitarios, profesionales e investigadores críticos, solidarios y comprometidos con la transformación social. Promueve la investigación dirigida a los «grandes problemas nacionales», a los sectores postergados, y a los sujetos políticos colectivos de la transformación de la sociedad en un sentido igualitario y la integralidad de funciones de investigación, extensión y docencia. La extensión está al mismo nivel de la enseñanza y la investigación, las tres se combinan e integran según el caso de formas diversas. Citado por Tommasino, donde establece que fue modificado de Cano, A., 2014. (Cuadro elaborado a partir de Castro y Fry [2013]; incorporando ideas de Altbach [2007]; Ordorika [2014; 2007]; Clark [2004]; OCDE [2012]; De Sousa Santos [2006]; González Casanova [2001] y Darcy Ribeiro [1968; 2006]). 
Revista Universidad en Diálogo • Vol. 9, N. ํㅡㄹ Julio-Diciembre, 2019 • 129-159

ISSN 2215-2849 • EISSN: 2215-4752

URL: http://www.revistas.una.ac.cr/index.php/dialogo/index CorReo ElECTRÓNICO: universidadendialogo@una.cr

DOI: http://doi.org/10.15359/udre.9-2.7

Sumamos a este análisis sobre la tendencia a implementar universidades donde la investigación, docencia y extensión operan desde paradigmas a favor de la mercantilización del conocimiento, dejando al margen valores y acciones sustantivas de la educación superior autónoma, fundamentales para superar inequidades en los contextos del continente más desigual, América Latina:

...En este sentido, es necesario reconocer que «extensión universitaria» es un referente nodal de la genealogía del movimiento de Reforma Universitaria ocurrido en América Latina en la primera mitad del siglo XX, que tuvo en los sucesos de Córdoba de 1918 uno de sus hitos (Carlevaro, 2002; Tünnermann, 2000). Y desde esa raíz, en muchas universidades del continente, «extensión» ha sido un significante que ha permitido articular proyectos político-académicos capaces de disputar los modos hegemónicos de hacer universidad, procurando vincular los procesos de enseñanza y creación de conocimiento con los grandes problemas nacionales y las necesidades de los sectores populares de la sociedad. (Tommasino y Cano, 2016, p. 5)

Es menester rescatar que la autonomía universitaria y la libertad de cátedra en el contexto actual sirven como principios para la acción de quien ejerce la academia para el desarrollo de las áreas de extensión, de investigación y docencia, siguiendo de igual forma los fines y valores de la entidad universitaria. La autonomía y el derecho a la libertad de cátedra implica un compromiso de la academia en reciprocidad con la sociedad, dentro de los componentes sustantivos específicos que ejecutan y promueven, basados en la búsqueda de la equidad y del compromiso social, en su condición de universidades públicas de carácter estatal y autónomo. La exigencia de la OCDE para el desarrollo de la investigación y la docencia, como áreas prioritarias para la generación del conocimiento, deja de lado un área estratégica y sustantiva como la extensión, cuyo rol en la generación del conocimiento resulta fundamental desde una perspectiva de interculturalidad. La extensión ${ }^{19}$ seguirá siendo parte de la res-

19 Según Ardila, citado por León (2012, p. 8): «Las políticas de extensión e investigación están condicionadas por el modelo de desarrollo del gobierno de turno, que en los últimos 20 años han sido invariablemente neoliberales. Para citar un ejemplo, mientras en la Universidad Nacional de Colombia entre los años 2009 y 2011 se implementaron en Bogotá 1250 proyectos de extensión relacionados de educación continua y permanente y 678 de servicios académicos, en el mismo lapso de tiempo se aprobaron nueve de extensión solidaria. Por citar otro, en Chocó, el departamento con mayor pobreza y miseria del país, los proyectos en los mismos años fueron: 269 de educación continua, 139 de servicios académicos y cero de extensión solidaria (Universidad Nacional de Colombia, 2012). Si bien muchos de los de educación continua y de servicios académicos son internos de la Universidad y muchos otros con organizaciones gubernamentales, lo que impera en casi todos los casos es el fin de obtener recursos económicos independientemente de la población beneficiada y el impacto social que estos proyectos puedan tener» (Ardila, 2011). 
puesta digna e incluyente que las universidades públicas den a los sectores con menos acceso a los beneficios del desarrollo, cuestionando sus condiciones de exclusión y marginalidad, sustento político de la Reforma de Córdoba en su propuesta de articulación entre la universidad-sociedad y el Estado.

\section{Los cambios institucionales urgentes en la educación universitaria en relación con la autonomía y la libertad de cátedra}

Si la Reforma de Córdoba se sustentó en argumentos para la defensa de la autonomía universitaria y de la libertad de cátedra, en el marco de desiguales relaciones de poder o tensiones sociales, es importante reflexionar sobre lo planteado por Jacinto Ordóñez, refiriéndose a los desafíos que plantea la globalización en el campo educativo,

En el campo educativo seguimos este mismo patrón. Hemos dicho que, en el tiempo de la Colonia, en la América Latina se fundaron universidades a espaldas de las necesidades existentes en estos pueblos. Eso mismo pasó en el tiempo de la educación liberal, se cambió la forma sin cambiar la academia. En los tiempos del liberalismo económico, el mismo fenómeno pareciera que estuviera presente, a pesar de los beneficios que en muchos aspectos pudo traer la importación de tecnologías, a la América Latina le ha costado caro modernizar sin cambiar, haciendo más profundas las contradicciones de las cuales hemos venido hablando. Dice Escobar Navia que la modernización ha sido hecha a pedazos porque también a pedazos se ha importado, los beneficios han sido parciales porque parciales han sido nuestros cambios. Se hace necesario pues, asumir el cambio no sólo porque lo impone la globalización sino porque su punto de referencia debe ser las necesidades de nuestros propios pueblos. (s. f., p. 10)

¿Qué elementos del contexto actual amenazan a estos dos constructos sociales de la autonomía y la libertad de cátedra? Tal como señala De Sousa,

Quien trabaja hoy en la universidad sabe que las tareas universitarias están dominadas por el corto plazo, por las urgencias del presupuesto, la competencia entre facultades, el empleo de los licenciados, etc. en la gestión de estas urgencias, florecen tipos de profesores y de conductas que poca utilidad y relevancia tendrían si en vez de urgencias, fuese necesario identificar y potenciar las emergencias donde se anuncia el largo plazo. Este estado de cosas, que se debe ciertamente a una pluralidad de factores, no puede 
con todo dejar de ser pensado en conjunción con las señales que poderosos actores sociales van dando desde el exterior de la universidad. ¿Cuál es el retorno social de pensar el largo plazo, de disponer de espacios públicos de pensamiento crítico e incluso para la producción de conocimiento más allá del exigido por el mercado? En la lógica del Banco Mundial la respuesta es obvia: el retorno es nulo, si existiese, sería peligroso, y si no fuese peligroso, no sería sustentable, pues estaría sujeto a la competencia de los países centrales que tienen en este dominio ventajas comparativas inequívocas. Si esta lógica global y externa no encontrase terreno propicio para ser apropiada local e internamente, no sería por cierto peligrosa. (2017, pp. 94-95)

Esta cita es parte de las críticas que han conducido a De Sousa (2007) a caracterizar lo que él denomina un revés en la posición de legitimidad y hegemonía de las universidades públicas en los últimos casi cuarenta años, producto, en parte, de la evolución del conocimiento convencional universitario al promovido por las tecnologías de la información y la comunicación (TIC), que generan cambios en las relaciones entre conocimiento e información y entre formación y ciudadanía.

Estos elementos, entre otros, derivados de este contexto histórico que viven las universidades públicas hace algunas décadas, hacen que De Sousa proponga una reforma universitaria contrahegemónica:

El objetivo consiste en recuperar el papel de la universidad pública en la definición y resolución colectiva de los problemas sociales, que ahora, aunque sean locales o nacionales, no se resuelven sin considerar su contextualización global. El nuevo contrato universitario parte así de la premisa de que la universidad tiene un papel crucial en la construcción del lugar del país en el mundo polarizado entre globalizaciones contradictorias (2007, p. 55)

Agrega que ese objetivo debe estar al margen de objetivos mercantilistas ${ }^{20}$ y lo define como una globalización alternativa y solidaria. Continúa Boaventura de

20 Robinson advierte sobre el peligro del capitalismo postfordista como un ciclo de acumulación mercantilista que ha profundizado el apartheid social, mismo que se revela en datos presentados por el autor: «...basado en el reporte de la ONG Oxfam sobre la desigualdad global, apropiadamente titulado "Riqueza: teniéndolo todo y queriendo más", se dice que el 48\% de la riqueza mundial se concentró en los más ricos en 2014, arriba de $44 \%$ más de $50 \%$ de la riqueza mundial para el 2016. El reporte de Oxfam señaló que el $80 \%$ restante tuvo que conformarse apenas con el $5.5 \%$ de esta riqueza. En términos simples, el mundo enfrenta una estructura trifurcada del 1\%, el 20\% y el $80 \%$ (Robinson, 2016, p. 2). La traducción es de Juliana Benavides: «...based in NGO Oxfam Report released in global inequality, aptly titled "Wealth: Having It All and Wanting more", of humanity owned 48 percent of the world's wealth in 2014, up from 44 more than 50 percent of the global wealth by $2016 \ldots$ The Oxfam Report noted that the richest whereas the remaining 80 percent had to make do with just 5.5 percent of the that wealth. In simplified terms, the world faces a trifurcated structure of the 1 percent, the 20 percent, and the 80 percent» (Robinson, 2016, p. 2). 
Sousa analizando de forma crítica la necesidad del proceso de reforma universitaria, al referirse a la resistencia de los países «periféricos y semiperiféricos», como estrategias de «globalización alternativa», frente a la crítica esperada naturalmente por los sectores neoliberales, que le exigen rendición de cuentas, como parte de los errores cometidos por el Estado en el pasado.

La universidad pública sabe que sin proyecto nacional sólo hay contextos globales y estos son demasiado poderosos para que la crítica universitaria de los contextos no acarree la propia descontextualización de la universidad. El «exceso de lucidez» de la universidad le permite denunciar que «el emperador va desnudo» y es por eso que la reforma de la universidad será siempre diferente de todas las demás. (De Sousa, 2017, p. 56)

Como consecuencia de la democratización de las universidades públicas desde 1918 con la Reforma de Córdoba, muchos ejemplos se podrían citar sobre el aporte de las universidades públicas estatales en América Latina a la movilidad social de miles de latinoamericanos de diferentes clases sociales, que han podido acceder a la educación superior universitaria, generando beneficios a nivel local o en procesos nacionales o internacionales de desarrollo y a la gestión del conocimiento de forma autónoma.

Dentro de esta lógica autonómica, de igual manera las universidades han cumplido un rol fundamental, basadas en principios de reciprocidad, solidaridad e igualdad, a partir de procesos enmarcados en programas de extensión, docencia e investigación dirigidos a los más pobres, mismos que han promovido el desarrollo nacional de forma paralela o conjunta con el Estado y la sociedad.

En todos estos casos, las universidades públicas han defendido y defienden la autonomía universitaria y libertad de cátedra. También es claro que en países como Chile o Colombia, universidades públicas como la Universidad de Chile y la Universidad Nacional de Colombia, respectivamente, ya fueron «reconvertidas» según los requerimientos administrativos del Estado y el marco jurídico-funcional de las últimas décadas que las obliga a gestionar sus propios recursos, que superan a los exiguos fondos asignados por este, condición que limita el ejercicio de su autonomía institucional y su capacidad de respuesta ante la creciente demanda social, lo que reduce su legitimidad y promueve su mutilación académica.

Con esta nueva tendencia financiera para las universidades públicas con reducido apoyo financiero estatal, se fortalece el trinomio universidad-empresaEstado, dejando atrás su mandato histórico en protección del bienestar público mediante el trinomio universidad-sociedad-Estado. 
Revista Universidad en Diálogo • Vol. 9, N. ², Julio-Diciembre, 2019 • 129-159

ISSN 2215-2849 • EISSN: 2215-4752

URL: http://www.revistas.una.ac.cr/index.php/dialogo/index CorReo ElECTRÓNICO: universidadendialogo@una.cr DOI: http://doi.org/10.15359/udre.9-2.7

\section{La internacionalización de las universidades y la cooperación internacional}

El campus universitario, como referencia territorial, ha sido parte del imaginario social latinoamericano para la definición de la autonomía universitaria. Si bien el concepto de espacio sigue siendo un constructo social importante ligado a la definición y reivindicación de la autonomía y libertad de cátedra, las universidades públicas no deben perder la perspectiva del contexto actual en la generación del conocimiento. ${ }^{21}$ Tünnerman alude a varios aspectos a considerar sobre la necesidad de adaptarse a la internacionalización ${ }^{22}$ no neoliberal ${ }^{23}$ de la educación en relación con el carácter internacional del conocimiento contemporáneo:

a) La existencia de una cada vez mayor academia mundial, formada por científicos y científicas que forman redes que utilizan el ciberespacio como medio de comunicación.

b) La emergencia de un conocimiento sin fronteras y de la sociedad de la información, en un mundo cada vez más globalizado. (2008, p. 14)

$21 \quad$ La Declaración Mundial sobre la Educación Superior, citada por Tünnermann (2008, p. 5), señala en su preámbulo que «si se carece de instituciones de educación superior e investigación adecuadas que formen una masa crítica de personas cualificadas y cultas, ningún país podrá garantizar un auténtico desarrollo endógeno y sostenible; los países en desarrollo y los países pobres, en particular, no podrán acortar la distancia que los separa de los países desarrollados industrializados». Y el artículo primero de la Declaración reafirma «la necesidad de preservar, reforzar y fomentar aún más las misiones y valores de la educación superior, en particular la misión de contribuir al desarrollo sostenible y el mejoramiento del conjunto de la sociedad». «La sociedad del conocimiento, dice a su vez la Declaración de Santo Domingo ("La ciencia para el siglo XXI"), (marzo, 1999), implica potenciar la capacidad tecnológica combinando formas tradicionales y modernas que estimulen la creación científica y hagan viable el desarrollo humano sostenible».

22 Cordera y Santamaría señalan que en la actualidad conviven varios tipos de internacionalización que no han permitido la construcción de una definición general aceptada por la mayoría • Internacionalización institucional: Las variantes de esta modalidad incluyen, por ejemplo, la introducción en los planes de estudio de asignaturas aisladas vinculadas con temas internacionales; el diseño de programas que incorporan la dimensión internacional para proporcionar a sus alumnos una formación universal e intercultural en determinadas disciplinas; así como la realización de proyectos de investigación y/o desarrollo interinstitucionales.

-Internacionalización regional, subregional y entre regiones: Esta modalidad se basa en programas multilaterales en los que se desarrolla el aprendizaje de idiomas, la vinculación universidad-empresa y la movilidad estudiantil, de personal académico y de profesionales. Ejemplos notables de esta cooperación son los programas que lleva a cabo la Unión Europea, algunos de los cuales han dispuesto de espléndidos financiamientos y amplia difusión, tales como ERASMUS, TUNING y LEONARDO DA VINCI (2008, p. 70).

23 Cordera y Santamaría: «Por otra parte, el carácter internacional en la educación también ha sido, en ocasiones, un resultado de la dominación económica que se ha generado a partir del comercio y los flujos financieros auto regulados o de libre mercado, llevando al quehacer universitario a depender exclusivamente de beneficios monetarios» (2008, p. 70). 
Sobre el concepto mismo de internacionalización, Cordera y Santamaría hacen la siguiente referencia:

El concepto de internacionalización no es reciente en la educación superior. Prueba de ello es la noción de la validez universal de los títulos, que desde sus orígenes definió a la universidad medieval, como entidad abierta a todas las naciones del mundo conocido hasta entonces. De la misma manera, en épocas posteriores y de forma permanente, las instituciones de educación superior han realizado esfuerzos para incorporar el conocimiento internacional en sus programas, o para establecer vínculos de colaboración entre sí, ya sea por medio de actividades conjuntas, o mediante el intercambio de estudiantes y personal académico. (2008, p. 69)

Cordera y Santamaría (2008) aprueban el discurso institucional internacional de la UNESCO en esta materia, al señalar que protege la creación de redes internacionales basadas en principios de reciprocidad, solidaridad e igualdad, mediante instrumentos normativos a nivel regional e internacional que permita el reconocimiento de estudios y diplomas (incluyendo los que atañen a conocimientos, competencias y aptitudes de los profesionales), que promuevan entre los sistemas nacionales y entre ellos el ascenso o la movilidad académica.

La internacionalización se ha convertido en un reto para las universidades públicas. En un contexto global, muchas buscan la mejor forma de hacerlo sin perder la perspectiva de sus fines y valores, basados en la institucionalidad latinoamericana defendida desde 1918 con la Reforma de Córdoba, la autonomía y la libertad de cátedra.

\section{La cooperación internacional como medio para lainternacionalización}

En relación con la cooperación internacional como medio para la internacionalización, los autores Cordera y Santamaría (2008) plantean que fue en la década de los noventa que las acciones dirigidas hacia la cooperación internacional en materia educativa creció considerablemente como resultado de los cambios tecnológicos, conocido como desarrollo de las tecnologías de la información y la comunicación y el avance en el acceso a los conocimientos, así como a la gestión de recursos financieros para acceder de forma sistemática y constante a los estudios, a la calidad de enseñanza, investigación y extensión, a la mejora de los programas, las posibilidades de empleo y la migración de profesionales, entre otros. De forma complementaria afirman los autores, 
No obstante, a partir de la década de 1990, las actividades de cooperación internacional en el ámbito educativo han tenido una notable expansión. Esto ha sido el producto, en parte, de los avances tecnológicos en materia de información y comunicación, así como de la velocidad y facilidad con la que se tiene acceso a los conocimientos (aspectos que las universidades no pueden soslayar, ni menos aún, quedarse al margen); pero también de la necesidad de encontrar soluciones a los problemas que la educación superior comparte en el ámbito mundial, en lo que se refiere al financiamiento, la igualdad de condiciones de acceso y permanencia en los estudios, la mejora y conservación de la calidad de la enseñanza, la investigación y los servicios, la pertinencia de los programas, las posibilidades de empleo y la migración de profesionales, entre otros. (Cordera y Santamaría, 2008, p. 69)

Siguiendo esta lógica de la necesaria gestión de la cooperación para la internacionalización, que incluso De Sousa plantea como parte de la reforma universitaria contrahegemónica:

La reforma orientada a una globalización solidaria de la universidad como bien público tiene que partir de la solidaridad y de la cooperación al interior de la red nacional de universidades; esta red nacional debe estar desde el comienzo transnacionalizada, es decir, debe integrar universidades extranjeras interesadas en formas de transnacionalización no mercantil. Obviamente que esas relaciones -llamadas hoy «relaciones internacionales»- ya existen; solo que deben ser intensificadas hasta el punto que sean tan constitutivas de la red, que dejen de ser consideradas externas o apéndices. (2007, p. 81)

El mismo De Sousa (2007) continúa ampliando la propuesta, sobre la cual recalca que las relaciones y los acuerdos a nivel bilateral y multilateral ya existentes deben ser potenciados según principios de reciprocidad y al margen de regímenes comerciales, dentro de la lógica de la globalización alternativa para las universidades públicas.

En este sentido, Tünnerman (2008) advierte que el denominado tercer sector debe seguir los lineamientos de la Declaración Mundial sobre la Educación Superior, que propugna la cooperación horizontal, solidaria, basada en el enfoque de interculturalidad, respetuosa de la idiosincrasia e identidad de los actores participantes, mediante el diseño de espacios académicos ampliados, como las redes interuniversitarias y los hermanamientos solidarios. Señala que la transnacionalización, que no es lo mismo que la internacionalización, 
promueve la vinculación de las universidades a entidades filiales de tercer nivel extranjeras, en un servicio ligado a las reglas del mercado, mediante criterios asistenciales como la venta de franquicias académicas, a la creación de universidades corporativas, auspiciadas por las grandes empresas transnacionales, los programas multimedios y las universidades virtuales, controladas por universidades y empresas de los países más desarrollados.

Derivado de este planteamiento, continúa su defensa de la internacionalización del tercer sector estatal,

El concepto clave para resguardar, en un mundo globalizado y de mercados abiertos y competitivos, la autonomía, la libertad de cátedra y los principios esenciales que caracterizan el quehacer universitario, tal como hasta ahora lo hemos conocido, es el criterio proclamado por la aludida Declaración Mundial sobre la Educación Superior, que nítidamente define la educación superior como un bien público y el conocimiento generado en ella como un bien social al servicio de la humanidad. (Tünnermann, 2008, p. 2)

En este estudio realizado por Tünnermann (2008) sobre la calidad de la educación superior en Centroamérica y su acreditación, queda esclarecido que tanto la autonomía como la libertad de cátedra son defendidas por los sistemas normativos y regulatorios de la educación superior en Centroamérica, a nivel público y privado, en tanto estas últimas respondan a los intereses públicos de la acreditación misma.

Es relevante rescatar el planteamiento de Cordera y Santamaría (2008), Tünnermann (2008) y De Sousa (2007) en relación con las necesarias articulaciones que promuevan el desarrollo de la educación superior universitaria, en el entendido de que el desarrollo de capacidades de la sociedad requiere acciones especiales para el abordaje específico de inclusión de los sectores que se mantienen al margen de los beneficios del capitalismo. La internacionalización ha demostrado ser un espacio de desarrollo de la sociedad académica, y la gestión del conocimiento y la cooperación un instrumento para fortalecerla, en el marco de procesos autónomos que promueven la libertad de cátedra.

\section{Conclusiones}

La autonomía y la libertad académica o de cátedra siguen vigentes desde la Reforma de Córdoba en 1918, pues los desafíos contextuales, en relación con el espacio y tiempo donde inciden, responden a una interacción entre estas y la 
Revista Universidad en Diálogo • Vol. 9, N. ํㅡㄹ Julio-Diciembre, 2019 • 129-159

ISSN 2215-2849 • EISSN: 2215-4752

URL: http://www.revistas.una.ac.cr/index.php/dialogo/index CoRReo ELECTRÓNICO: universidadendialogo@una.cr DOI: http://doi.org/10.15359/udre.9-2.7

sociedad, más allá de las medidas estándar de los organismos internacionales financieros, con los cuales interactúan. El lugar público que ocupan estos dispositivos universitarios, la formación que ofrece y los conocimientos que genera siguen siendo legítimos para una sociedad que requiere servicios educativos universitarios para su desarrollo integral y generación del pensamiento crítico.

A pesar de la Reforma de Córdoba, se infiere de las lecturas anteriores que las universidades son la respuesta a las necesidades de un Estado desarrollista, mismas que han seguido un modelo de relaciones no siempre recíproco con la sociedad nacional e internacional en que se encuentran insertas. Por tanto, sigue siendo un desafío, la búsqueda de la reciprocidad y el reconocimiento a la interculturalidad entre universidad-sociedad, reconociendo y adaptándose a los cambios generados por aspectos como el conocimiento pluriuniversitario, la revolución de las tecnologías de la información y la comunicación (TIC) que han potenciado interacciones inimaginables para las sociedades académicas de las universidades públicas latinoamericanas, más allá de su tradicional ámbito para el ejercicio de la docencia, extensión e investigación, dentro de sus respectivos campus universitarios y sus contextos sociales inmediatos.

La falta constante de presupuesto en las universidades públicas ha generado una crisis de su autonomía, e incluso desde el punto de vista constitucional, en el caso de los países que así la reconocen. La falta de cumplimiento de este derecho por parte de los diferentes Gobiernos violenta los derechos humanos, tales como el derecho a la educación, a la libertad de cátedra, pero sobre todo al estatus jurídico de estas como entes autónomos.

De igual manera, la globalización neoliberal, como la denomina Tünnermann, especialmente a partir de la década de los ochenta, ha ejercido, mediante diversos mecanismos de control político, presión sobre la denominada autonomía universitaria (frente a la crisis financiera universitaria, el aumento de los controles de los Ministerios de Hacienda y Educación al estilo Banco Mundial, a la mayor presión social por demanda de este servicio público, entre otros), que en algunos casos conducen hacia la privatización de la educación mediante corporaciones privadas y globalizadas que responden a un mercado que demanda conocimiento en el marco de actividades académicas de excelencia, pero dentro de lógicas mercantilistas y empresariales pensadas desde el diseño y desempeño institucional, exigidos desde organismos financieros tales como el BM o el BID, mismos que otorgan préstamos a universidades con presupuestos deficitarios y demandas sociales cada vez mayores. 
Las universidades públicas compiten con la creación de un mercado que conduce a la privatización de la educación universitaria, dentro del proceso de la globalización neoliberal que incluye de forma paralela los factores de amenaza externa ya mencionados.

Las universidades públicas son actores que contribuyen a equilibrar la desigualdad económica y social frente a un mundo cada vez más desigual, pues una parte importante de su esencia corresponde al compromiso social frente a la sociedad, para defender a los sectores que están quedando fuera de los beneficios del sistema capitalista actual. Este rol, heredado del Estado de bienestar, que le asegura los recursos para su existencia debe ser defendido en nombre de la autonomía, que le permitirá seguir siendo vigilante de procesos incluyentes y democráticos. El apartheid social caracterizado por Robinson frente a un mundo con una creciente desigualdad social debe ser combatido críticamente con propuestas y acciones que identifiquen las causas y cómo superarlas, sin miedo a la mutilación académica.

El relacionamiento a nivel político y social de las universidades públicas debe corresponder a los intereses de los sectores populares en mayores condiciones de desigualdad social y en coordinación definir las estrategias institucionales.

La libertad de cátedra es parte de la autonomía académica, entendiendo a las universidades como sociedades académicas con racionalidad sustantiva y operativa particular, aunque en algunos casos sujetos a muchos errores, que han marcado históricamente giros necesarios en el desarrollo interno de las mismas, como fue la Reforma de Córdoba. Estos giros o reformas deben ser replanteados de forma sistemática y crítica, dentro de una lógica de equidad y compromiso social universitario, como le corresponde según sus principios, fines y valores, relacionados con la naturaleza misma de la misión universitaria latinoamericana promovida desde 1918.

\section{Referencias bibliográficas}

Baño. R. (2017). Senador y académico de FACSO. ¿Qué es una Universidad Pública? Recuperado de http://www.facso.uchile.cl/noticias/67245/ que-es-una-universidad-publica

Brunner, J. (2010). Educación superior en América Latina. Centro de Políticas Comparadas de Educación. Universidad Diego Portales. Santiago de Chile. 
Cordera, R. y Santamaría, R. (abril-junio, 2008). Internacionalización, autonomía y calidad de la educación superior: elementos para la integración de América Latina y el Caribe. Universidades, núm. 37, 6976. Recuperado de http://www.redalyc.org/articulo.oa?id=37311274006

Comboni, S. S. y Juárez, N. J. (1997). La educación superior en América Latina: perspectivas frente al siglo XXI. Política y Cultura, núm. 9, invierno, 7-27. Universidad Autónoma Metropolitana, Unidad Xochimilco Distrito Federal, México. Recuperado de http://www. redalyc.org/articulo.oa?id=26700902

De Sousa, B. (2007). La universidad en el siglo XXI. Para una reforma democrática y emancipatoria de la universidad. CIDES-UMSA. Bolivia.

Hernández, G. (1985). Consideraciones sobre la libertad de cátedra (manuscrito inédito). Heredia, Costa Rica.

López y Rivas, G. (2016). América Latina y el capitalismo global: análisis de la obra de William I. Robinson, «América Latina y el capitalismo global: una perspectiva crítica de la globalización». Recuperado de http://www.lahaine.org/america-latina-y-el-capitalismo

Ordóñez, J. (s.f.). Ética y educación superior en la era de la globalización, perspectiva latinoamericana. Red de Bibliotecas Virtuales de Ciencias Sociales de América Latina y el Caribe. CLACSO. Recuperado de http://www.clacso.org.ar/biblioteca

Ordorika, S. I. (2006). Educación superior y globalización: las universidades públicas frente a una nueva hegemonía. Andamios, Andamios, 3(5), 3147. doi: https://doi.org/10.29092/uacm.v3i5.340

Oñativia, F. (2016). La Reforma Universitaria de 1918 en Argentina. ¿Qué fue la Reforma Universitaria? La Izquierda Diario. Recuperado de http://www. laizquierdadiario.com/LaReforma-Universitaria-de-1918-en-Argentina

Pastrana, F. y Castro, R. F. (2015). The long road to state-building in Latin America and its impact on regionalization processes. Papel Político, 20(2), 523-546. doi: https://doi.org/10.11144/Javeriana.papo20-2.lrs1

Robinson, W. (2015). América Latina y el capitalismo global. Una perspectiva crítica de la globalización. México: Siglo XXI Editores. 
Robinson, W. (2017). Reflexiones sobre una teoría del capitalismo global. Universidad Nacional, Costa Rica, 7-11 AGOSTO 2017. Heredia. Presentación (diapositivas PPT).

Tommasino y Cano (enero-marzo, 2016). Modelos de extensión universitaria en las universidades latinoamericanas en el siglo XXI: tendencias y controversias. Revista Universidades, Año LXVI, Nueva época, núm. 67.

Tünnermann, B. C. (1991). Historia de la universidad en América Latina: de la época colonial a la Reforma de Córdoba. San José, Costa Rica: EDUCA.

Tünnermann, C. (2005). La autonomía universitaria frente al mundo globalizado. Unión de Universidades de América Latina (UDUAL). Santo Domingo, República Dominicana.

Tünnermann, C. (2008a). La autonomía universitaria en el contexto actual. Universidades, núm. 36, pp. 19-46. Unión de Universidades de América Latina y el Caribe. Distrito Federal. Recuperado de http://www.redalyc. org/articulo.oa?id=37312909004

Tünnermann, B. C. (2008b). La calidad de la educación superior y su acreditación: la experiencia centroamericana. Avaliação: Revista da Avaliação da Educação Superior (Campinas), 13(2), 313-336. Doi: https://doi.org/10.1590/S1414-40772008000200005

Wallerstein, I. (1999). Impensar las ciencias sociales. Límites de los paradigmas decimonónicos. México: Editorial Siglo XXI. 
